
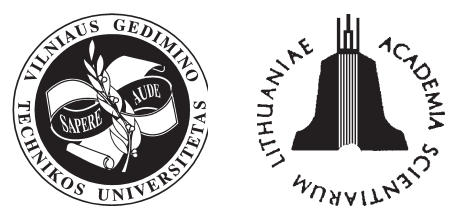

ISSN 1648-4142 TRANSPORT

http:/www.vtu.lt/english/editions

TRANSPORT - 2005, Vol XX, No 2,73-77

\title{
MOTORS FOR TRAM DRIVES
}

\section{Tadeusz Glinka ${ }^{1}$, Barbara Kulesz ${ }^{2}$, Mieczysław Jakubiec ${ }^{3}$}

1,2 Dept of Electrical Engineering in Transport, Silesian University of Technology, ul. Akademicka 10, 44-100 Gliwice, Poland, phone/fax (+4832) 2371258, e-mail tglinka@polsl.gliwice.pl, bklulesz@polsl.gliwice.pl

\author{
${ }^{3}$ BOBRME Komel, al. Roździeńskiego 188, 40-203 Katowice \\ phone (+4832), 2582041, fax (+4832) 2599948, e-mail info@komel.katowice.pl
}

Received 2004-11-01; accepted 2005-01-25

\begin{abstract}
This paper compares five different motor types used in variable speed drives: a dc motor with a mechanical commutator and with electromagnetic or permanent magnets excitation, a cage induction motor, asynchronous cascade with a slip-ring motor and a brushless motor with PM excitation. These motors are to be used for tram drive and they should all be characterised by identical external dimensions and a cooling system. Rated power and efficiency are the principal comparison criteria.
\end{abstract}

Keywords: electric traction, dc series motor, dc brushless motor, permanent magnets, drive motors.

\section{Introduction}

The paper investigated different electric motors used in variable speed drives. It is in these drives only that it is worthwhile to use dc motors with an electronic or mechanical commutator. The variable speed drives are used in the following cases:

- when changes in speed are required by the duty algorithm of the drive (e.g. roll mill drive),

- $\quad$ when the drive should operate at minimum energy consumption - energy-saving drive.

Energy-saving drives are preferable from the viewpoint of environmental protection.

Energy-saving operation is achieved when the drive is run at minimum speed compatible with the requirements of the engineering process.

Variable speed drives can be equipped with the following motor types (Fig 1):

- $\quad d c$ motor $(\mathrm{Ma})$ with electromagnetic excitation supplied from a power electronics converter (rectifier) ac/dc,

- $\quad d c$ motor $(\mathrm{Mb})$ excited by permanent magnets $(\mathrm{NdFeB})$ placed in the stator supplied from a power electronics converter (rectifier) ac/dc,

- cage induction motor $(M c)$ supplied from a power electronics converter (inverter) ac/dc/ac,

- asynchronous cascade consisting of slip-ring induction motor $(M d)$ and inverter/transformer set used for transmitting electrical energy from the rotor to the power network,
- $\quad$ brushless motor (Me) excited with permanent magnets $(\mathrm{NdFeB})$ placed in the rotor supplied from power electronics circuit called an electronic commutator ac/dc/ac. a)

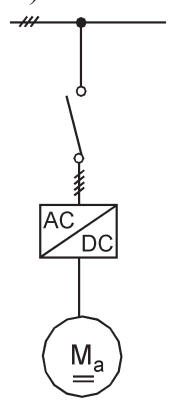

b)

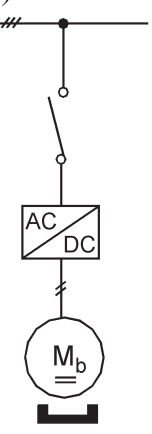

d)

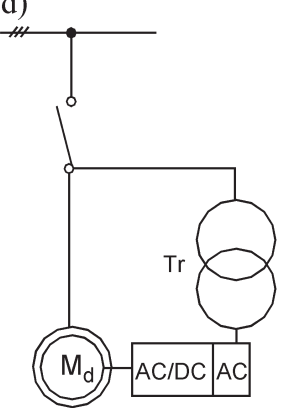

c)

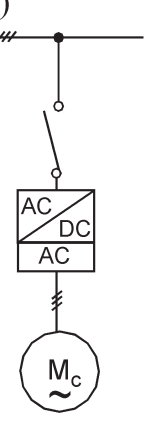

e)

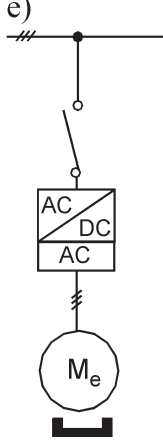

Fig 1. Different drive systems:

$\mathrm{a}-\mathrm{dc}$ motor with electromagnetic excitation; $\mathrm{b}-\mathrm{dc}$ motor with PM excitation; $\mathrm{c}$ - cage induction motor, $\mathrm{d}$ - asynchronous cascade; $\mathrm{e}-$ brushless motor with PM excitation 
The comparison of the rated power and efficiency of these motors is given in the paper. The comparison criteria are:

- external overall dimensions $D=400 \mathrm{~mm}$, I = $660 \mathrm{~mm}$ (Fig 2),

- identical cooling system (forced ventilation).

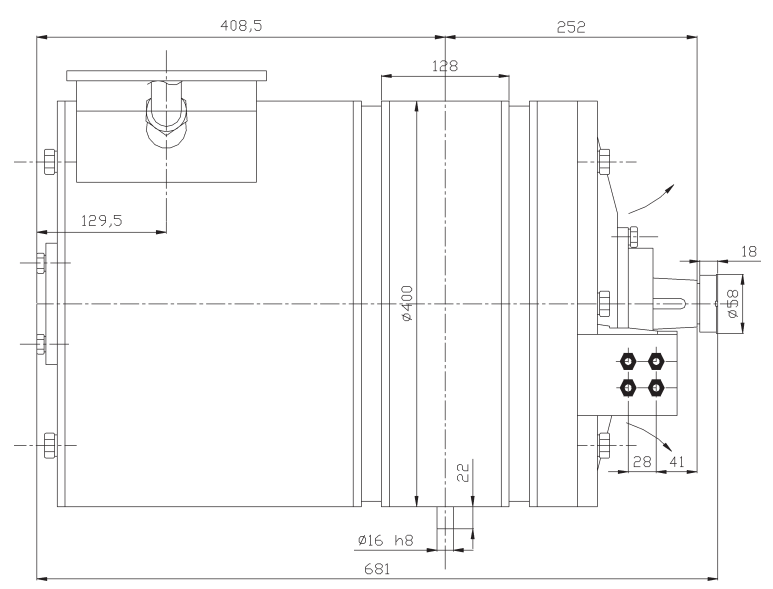

Fig 2. Traction motor Ma dimensional sketch

The dc motor with electromagnetic excitation $(\mathrm{Ma})$ is rated at $40 \mathrm{~kW}, 300 \mathrm{~V}, 1800 \mathrm{rpm}$, efficiency $89 \%$ is the reference base for the comparison.

In Poland de voltage is used for traction purposes. In railway it is $3000 \mathrm{~V}$ and in tram catenaries the voltage is $600 \mathrm{~V}$. Traditionally, the trams ere equipped with dc series motors with resistor starters. This technology has become an anachronism, however, for economical reasons mostly. Most of the existing drives are still in operation. It is worthwhile to investigate possible drive modernisations, assuming that the mechanical gearbox should not change and that only the motor and possibly a supply and starting system get altered. Hence, the dimensions of the alternate motor should be the same as those of a motor currently in operation. The following analysis of different drives is based on this assumption.

Dc motor (Ma) and induction motor (Mc) are currently manufactured and used in $105 \mathrm{~N}$ tram drive, their parameters are available. Dc motor $(\mathrm{Mb})$, brushless motor (Me) and slip-ring motor $(\mathrm{Md})$ parameters have been determined by analysis.

\section{Dc motor with a mechanical commutator}

Two possible designs of $d c$ motors with a mechanical commutator have been investigated:

- with electromagnetic excitation $(M a)$,

- with permanent magnets excitation - NdFeB magnets $(M b)$.

Dc motor with electromagnetic excitation $(M a)$ has been manufactured in Poland for more than 30 years. It is used in $105 \mathrm{~N}$ trams drive. Its ratings are:

$\mathrm{P}_{\mathrm{N}}=40 \mathrm{~kW} ; 300 \mathrm{~V} ; 150 \mathrm{~A} ; 1800 \mathrm{rpm}$; efficiency $89 \%$.

The power losses under nominal operating conditions are $\Delta P=4940 \mathrm{~W}$. These losses can be divided into:

- excitation winding losses $\Delta P_{f}=747 \mathrm{~W}$,

- armature winding losses $\Delta P_{a}=3200 \mathrm{~W}$,

- iron losses $\Delta P_{F e}=673 \mathrm{~W}$,

- mechanical losses $\Delta P_{m}=320 \mathrm{~W}$.

Rotor diameter $D_{a}=220 \mathrm{~mm}$; rotor active length $\mathrm{I}_{\mathrm{a}}=220 \mathrm{~mm}$; rotor volume $V_{a}=8,36 \mathrm{dm}^{3}$.

$D c$ motor with PM excitation (Mb) (Fig 3) has been constructed by modifying motor existing design. Permanent magnets (NdFeB) have been glued to the pole shoes on the air gap side.

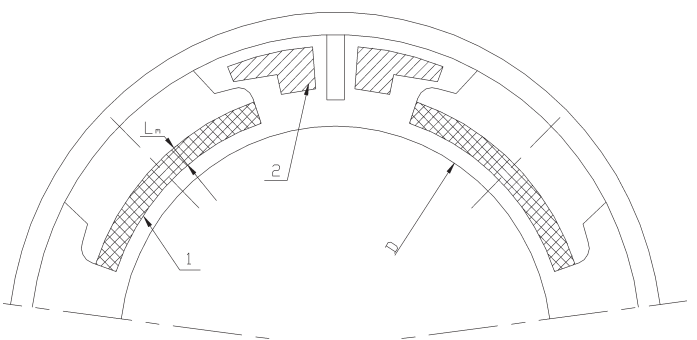

Fig 3. Magnetic circuit of tram motor Mb excited with permanent magnets (1) and with commutator poles winding

The excitation pole arc length of $\mathrm{Mb}$ motor has been assumed to be the same as in Ma motor $b_{a}=b_{b}=115 \mathrm{~mm}$ and commutation winding parameters have also been left unchanged. Indexes " $a$ " and " $b$ " relate to $M a$ and Mb motors, respectively. Since excitation winding is absent in Mb motor, the window cross-section between the main poles and commutation poles may be decreased, since this window contains commutation poles winding only.

Hence, rotor diameter of $M b$ motor can be increased. The rated power $\mathrm{P}_{\mathrm{Nb}}$ of $\mathrm{Mb}$ motor can be estimated from the formula [1]:

$$
P_{N b}=P_{N a}\left(\frac{V_{b}}{V_{a}}\right)^{4 / 3} \text {. }
$$

Diameter $D_{b}$ of the new motor will be greater, since the window cross-section between the main poles and commutation poles will be decreased. In Ma motor excitation coil two flat copper wires are placed near the pole. The height and width of these wires are $a=1,3 \mathrm{~mm}, \mathrm{~b}=20 \mathrm{~mm}$. A window in a new motor can be reduced in the radial direction by one wire width ( $b$ ) less radial length of PM $\left(I_{m}\right)$, or $\left(b-I_{m}\right)$ altogether. 
Maintaining the air gap induction and assuming that air gap width is equal to $\delta_{\mathrm{b}}=2 \mathrm{~mm}$ (in $M a \mathrm{mo}^{-}$ tor the air gap is equal to $\left.\delta_{\mathrm{a}}=3 \mathrm{~mm}\right), \mathrm{NdFeB} \mathrm{PM}$ length should be equal to $\mathrm{I}_{\mathrm{m}}=6 \mathrm{~mm}$. This is determined by calculating the induction at rotor surface when a magnetic circuit is excited with permanent magnets [2].

$\mathrm{Mb}$ motor rotor diameter and rotor volume will therefore be equal to:

$$
\begin{aligned}
& D_{b}=D_{a}+2 \cdot\left(b-l_{m}+\delta_{a}-\delta_{b}\right), \\
& V_{b}=\frac{\pi}{4} D_{b}^{2} \cdot l .
\end{aligned}
$$

$\mathrm{Mb}$ motor rated power at continuous duty ( $\mathrm{S} 1$ ) is determined by equation (1). Its rating is $\mathrm{P}_{\mathrm{Nb}}=56 \mathrm{~kW}$.

$M b$ motor efficiency will go up, since excitation losses $\Delta P_{f}$ are non-existent. The power losses in the main poles pole shoes will also be less, since the air gap for alternating components of the flux will be increased from $\delta_{a}=3 \mathrm{~mm}$ to $\delta_{b}+I_{m}=8 \mathrm{~mm}$. These losses are due to:

- $\quad$ slot pulsations of excitation magnetic flux,

- $\quad$ armature reaction flux pulsations due to power electronics converter. balance.

These losses are neglected in the overall power

Armature power losses in $\mathrm{Mb}$ motor will increase in proportion to rotor volume:

$$
\Delta P=\left(\Delta P-\Delta P_{f}\right) \cdot \frac{V_{b}}{V_{a}} .
$$

These losses $(\Delta P=5416 \mathrm{~W})$ are greater than total power losses in Ma motor. In order to keep the motor heat balance, total losses should not exceed $4940 \mathrm{~W}$ (value for Ma motor). This can be achieved by decreasing $\mathrm{Mb}$ motor rated power $\mathrm{P}_{\mathrm{Nb}}$ by $5 \%$, i.e. from $56 \mathrm{~kW}$ to $53 \mathrm{~kW}$. The power losses will go down to $\Delta P=4852 \mathrm{~W}$.

$\mathrm{Mb}$ motor efficiency is equal to:

$$
\eta=\frac{P_{N b} \cdot 100}{P_{N b}+\Delta P} .
$$

Efficiency is determined by equation (5). Its rating is $\eta=91,6 \%$.

To summarize, using the casing of Ma motor it is possible to design $\mathrm{Mb}$ motor with greater rated power and with higher efficiency.

Dc motor $M b$ excited with $\mathrm{NdFeB}$ permanent magnets will be a separately excited motor with one speed control range at constant torque. in Table.

\section{Cage induction motor Mc}

Cage induction motor $M c$ has been designed by the authors with identical dimensions as Ma motor and is currently being manufactured and employed as the main drive motor for $105 \mathrm{~N} \mathrm{~N}$ type trams. It is often installed in the tram during vehicle general overhaul, when the drive is modernized. Since there is no commutator, the active part of the winding is longer (i.e. stacking is longer) $l_{c}=300 \mathrm{~mm}$. Inner stator diameter is equal to $D_{b}=215 \mathrm{~mm}$. Inner rotor volume $V_{c}=10,9 \mathrm{dm}^{3}$ is almost the same as in Mb motor. Rated power of Mc motor is identical as in $\mathrm{Mb}$ motor and equal to $P_{N c}=53 \mathrm{~kW}$.

Power losses in Mc motor are determined on the basis of a motor test report (conducted by the manufacturer).

The rated parameters are: $P_{N c}=53 \mathrm{~kW}$; $\mathrm{U}_{\mathrm{N}}=380 \mathrm{~V} ; 60 \mathrm{~Hz} ; I_{1 N}=91,6 \mathrm{~A}[3]$.

Power losses are as follows:

- iron losses $\Delta \mathrm{P}_{\mathrm{Fe}}=600 \mathrm{~W}$,

- $\quad$ armature winding losses $\Delta P_{m 1}=1900 \mathrm{~W}$,

- rotor winding losses $\Delta P_{m 2}=2090 \mathrm{~W}$,

- mechanical losses $\Delta \mathrm{P}_{\mathrm{m}}=170 \mathrm{~W}$.

The power losses of Mc motor under rated operating conditions are $\Delta P_{N}=4760 \mathrm{~W}$.

Mc motor rated efficiency is determined as well as $M b$ motor. Its rating is $\eta=91,7 \%$.

Power factor is equal to:

$$
\cos \varphi_{\mathrm{N}}=\frac{\mathrm{P}_{\mathrm{NC}}}{\sqrt{3} \cdot \mathrm{U}_{\mathrm{N}} \cdot \mathrm{I}_{1 \mathrm{~N}}} .
$$

Power factor is determined by equation (6). Its rating is $\cos \varphi_{N}=0,88$.

The induction motor with scalar control can operate in two speed control ranges, i.e. constant torque range, then $l_{d}=l_{a}=220 \mathrm{~mm}$ and constant power range, then $n_{N} \leq n \leq n_{\max }$.

However, usually vector control is used since it improves the drive dynamics and brings it close to $d c$ motors dynamic properties.

Mc motors characteristics are presented in Table.

\section{Asynchronous cascade Md}

Asynchronous cascade consists of a slip-ring induction $M d$ motor and a frequency converter ac/dc/ac connected into rotor circuit - see Fig 1.

The active length of $M d$ motor will be similar (identical) to that of Ma motor $l_{d}=l_{a}=220 \mathrm{~mm}$, since slip rings take up the place allotted to the commutator in Ma motor. The inner stator diameter $D=215 \mathrm{~mm}$ will be the same as in Mc motor.

The rated power of $M d$ motor will be less than 
that of Mc motor. Roughly, it will decrease in proportion to length ratio $l_{d} / l_{c}$, since the diameter $D_{d}=D_{c}$ :

$$
P_{N d}=P_{N c} \frac{l_{d}}{l_{c}} .
$$

Rated power is determined by equation (7). It rating is $P_{N d}=38,8 \mathrm{~kW}$.

Iron losses, while induction remains the same, will also decrease by the same ratio $l_{d} / l_{c}$. Its rating is $\Delta P_{\text {Fed }}=440 \mathrm{~W}$.

Armature winding copper weight will be less by $8 \%$, since the end windings in $M c$ and $M d$ motors are identical. Mechanical losses will decrease at the same rate and their rating is $\Delta \mathrm{P}_{\mathrm{mld}}=1748 \mathrm{~W}$.

The rotor winding losses will not change, since even though the losses in the active parts of the winding fall down by $17 \%$, the losses in the end windings will rise as well as the losses in the slip-ring head. Therefore it has been assumed that $\Delta P_{m 2 d}=2090 \mathrm{~W}$.

The mechanical losses will increase $\Delta P_{m d}=320 \mathrm{~W}$.

Total power losses in Md motor at rated power are equal to $\Delta P_{N d}=4598 \mathrm{~W}$.

However, if the cooling factor is considered, the power losses may be increased up to $\Delta P_{N d}=\Delta P_{N c}=4760 \mathrm{~W}$, and then the rated power will also go up by ratio $4760 / 4898$ and is equal $\Delta P_{N d}=40 \mathrm{~kW}$.

Md motor rated efficiency is determined as well as $M b$ motor. Its rating is $\eta=89,4 \%$.

The reactive power of $M d$ motor will be less than the reactive power of Mc motor, approximately proportionately to the active length:

$$
\begin{aligned}
& Q_{d}=Q_{c} \frac{l_{d}}{l_{c}}, \\
& Q_{c}=\frac{P_{N_{c}}}{\eta_{c}} \sin \varphi_{c} .
\end{aligned}
$$

Taken into consideration equations (8) and (9) $Q_{d}=20 \mathrm{kVAr}$.

Md motor power factor is:

$$
\begin{aligned}
& \cos \varphi_{d}=\frac{P_{1 N_{c}}}{\sqrt{P_{1 N c}^{2}+Q_{d}^{2}}}, \\
& P_{N_{C}}=P_{N_{c}}+\Delta P_{N_{c}} .
\end{aligned}
$$

Power factor is determined by equation (10) and (11). Its rating is $\cos \varphi_{d}=0,91$.

Md motors rated parameters: voltage $\mathrm{U}_{\mathrm{N}}=380 \mathrm{~V} ; 60 \mathrm{~Hz}$; current flowing

$$
I_{N}=\frac{P_{N_{C}}}{\sqrt{3} \cdot U_{N} \cdot \cos \varphi_{d}}=74,7 \mathrm{~A} .
$$

Md motors characteristics are presented in Table.

\section{Dc brushless motor Me excited with permanent magnets}

The magnetic circuit of brushless Me motor with electronic commutator is shown in Fig 4.

Motor stator and stator windings are identical as in the induction Mc motor. The stacking length may remain unchanged and equal to $\mathrm{I}_{\mathrm{e}}=300 \mathrm{~mm}$ and the stator inner diameter may be equal to $D_{e}=215 \mathrm{~mm}$. It has also been assumed that air gap $\delta_{e}=1 \mathrm{~mm}$ and magnetic length of permanent magnets $\mathrm{I}_{\mathrm{m}}=4 \mathrm{~mm}$. The brushless Me motor with an electronic commutator, at load power $53 \mathrm{~kW}$ (continuous duty S1) will be characterised by better operating parameters than an induction motor [2].

Current flowing in the winding will possess the active component only:

$$
I_{1 N}=I_{1 N c} \cdot \cos \varphi_{c} .
$$

Me motor current flowing is determined by equation (12). Its rating is $I_{1 N}=80,6 \mathrm{~A}$.

Active power losses in the motor can be calculated from the formula:

$$
\Delta P=P_{0}+3 R_{1} I_{1 N}^{2}+\Delta P_{d}
$$

since power losses in the rotor and power losses in the stator winding caused by a current passive component are nil:

$$
\Delta P=\Delta P_{F e}+\Delta P_{m}+\Delta P_{m 1} \cdot \cos \varphi_{c}^{2} .
$$

Me motor power losses are determined by equation (14). Its rating is $\Delta P=2241 \mathrm{~W}$.

Md motor efficiency rises up to $\eta=95,9 \%$.

The efficiency of a brushless Me motor with an electronic commutator is higher by $4,2 \%$ than the

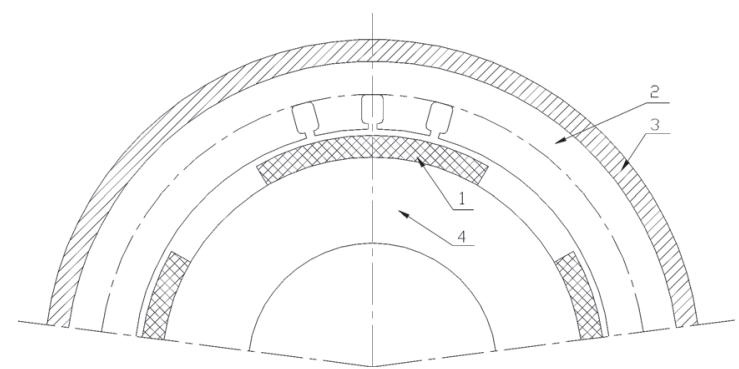

Fig 4. The magnetic circuit of a motor with an electronic commutator: 1 - permanent magnets $\mathrm{NdFeB}, 2$ - stator stacking, 3 - casing, 4 - ferromagnetic core 
Specification of basic parameters of motors intended for $105 \mathrm{~N}$ tram drive

\begin{tabular}{|c|l|c|c|c|c|c|c|}
\hline \multirow{2}{*}{ No } & \multicolumn{2}{|c|}{ Parameters } & \multicolumn{6}{|c|}{ Motor type } \\
\cline { 3 - 8 } & \multicolumn{2}{|c|}{ Ma } & Mb & Mc & Md & \multicolumn{2}{c|}{ Me } \\
\hline 1 & $\begin{array}{l}\text { Rated power for } \\
\text { continuous duty (SI), kW }\end{array}$ & 40 & 53 & 53 & 40 & 53 & 77 \\
\hline 2 & Rated voltage, V & 300 & 300 & 380 & 380 & 380 & 380 \\
\hline 3 & Input power, kW & 44,94 & 57,84 & 57,76 & 44,76 & 55,24 & 81,76 \\
\hline 4 & Power losses, W & 4940 & 4842 & 4760 & 47,60 & 2241 & 4760 \\
\hline 5 & Efficiency, \% & 89 & 91,6 & 91,7 & 89,4 & 95,9 & 94,1 \\
\hline
\end{tabular}

induction motor efficiency. However, if it is assumed that the heat exchange is identical as in Mc motor, then power losses can be increased up to $\Delta P=4760 \mathrm{~W}$, and rated power subsequently increases up to $P_{N}=77 \mathrm{~kW}$.

Hence a brushless Me motor with an electronic commutator can be designed on the basis of $\mathrm{Ma} \mathrm{mo-}$ tor dimensions. This new motor will be excited with permanent $\mathrm{NdFeB}$ magnets and it will be rated at $77 \mathrm{~kW}$. Its rated efficiency is determined and its rating is $\eta=94,1 \%$.

This motor type makes possible the achievement of the highest power and efficiency at the given volume. The motor operates as a dc motor excited with permanent magnets, i.e. only one range of speed control is available ( $T=$ const ); the speed varies as supply voltage changes.

This motor is also characterised by high torque overload capacity depending on allowable transistor currents and mechanical strength of the shaft, coupling and transmission.

Me motors characteristics are presented in Table.

\section{Recapitulation}

Table sets out characteristic parameters of 5 different $M a-M e$ motor types, all designed with the same external dimensions as shown in Fig 4.

\section{Conclusions}

- Variable speed drives can be designed with five different motor types shown in Fig 1.

- The brushless Me motor with an electronic commutator excited with permanent magnets is characterised by the best operational parameters. For the given motor volume the rated power and efficiency are the highest.

- The brushless motor with an electronic commutator is as reliable as a cage induction motor since there are no movable contacts, there are no active power losses in the rotor. It ensures the highest overload capacity of all the investigated motors.

\section{References}

1. Postnikov, I. M. Design of electrical machines (Проектирование электрических машин). Kijev: 1960 (in Russian).

2. Glinka, T. Electrical machines excited with permanent magnets (Maszyny elektryczne zbudzane magnesami trwałymi) yd. Pol. Śląskiej, Gliwice 2002, (in Polish) ISBN 83-7335-87-X.

3. Design specification and test reports of STD200L4 motor. 